\title{
Preoperative frailty parameters as predictors for outcomes after transcatheter aortic valve implantation: a systematic review and meta-analysis
}

\author{
M. S. van Mourik · J. F. Velu · V. R. Lanting · J. Limpens · B. J. Bouma · J. J. Piek · J. Baan · J. P. S. Henriques · \\ M. M. Vis
}

Published online: 18 March 2020

(C) The Author(s) 2020

\begin{abstract}
Guidelines suggest using frailty characteristics in the work-up for a transcatheter aortic valve implantation (TAVI). There are many frailty-screening tools with different components. The prognostic value of the individual parameters in frailty is as yet unclear. The objective of this systematic review and meta-analysis was to find and pool predictors for 1-year mortality after TAVI. We followed a twostep approach. First, we searched for randomised controlled trials on TAVI to identify frailty parameters used in these studies. Second, we searched for publications on these frailty parameters. Articles were included for pooled analysis if the studied frailty parameters were dichotomised with clear cutoff values based on common standards or clinical practice and reported adjusted hazard ratios (HR) of 1-year mortality after TAVI. We calculated pooled effect estimates of 49 studies based on dichotomised frailty scores (HR: 2.16, 95\% CI: 1.57-3.00), chronic lung disease (HR: 1.57, 95\% CI: 1.45-1.70), estimated glomerular filtration rate $<30 \mathrm{ml} / \mathrm{min}$ (HR: $1.95,95 \%$ CI: $1.68-2.29$ ), body mass index $<20 \mathrm{~kg} / \mathrm{m}^{2}$ (HR: 1.49 , 95\% CI: 1.09-2.03), hypoalbuminaemia (HR: 1.77, 95\%
\end{abstract}

M.S. van Mourik and J.F. Velu contributed equally.

Electronic supplementary material The online version of this article (https://doi.org/10.1007/s12471-020-01379-0) contains supplementary material, which is available to authorized users.

M. S. van Mourik · J. F. Velu · V. R. Lanting · B. J. Bouma ·

J. J. Piek · J. Baan · J. P. S. Henriques · M. M. Vis (西)

Department of Cardiology, Amsterdam UMC, University

of Amsterdam, Amsterdam Cardiovascular Sciences,

Amsterdam, The Netherlands

m.m.vis@amc.uva.nl

J. Limpens

Medical Library, Amsterdam UMC, University of

Amsterdam, Amsterdam, The Netherlands
CI: 1.38-2.25), anaemia (HR: 2.08, 95\% CI: 0.93-4.66), low gait speed (HR: 13.33, 95\% CI: 1.75-101.49) and Katz activities of daily living (ADL) score of 1 or more deficits (HR: 5.16, 95\% CI: 0.77-34.47). Chronic lung disease, chronic kidney disease, underweight, hypoalbuminaemia, a low frailty score, anaemia, low gait speed and an ADL deficiency were associated with worse 1-year outcomes after TAVI.

Keywords Transcatheter aortic valve implantation Frailty $\cdot$ Predictor $\cdot$ Outcome $\cdot$ Mortality

\section{Introduction}

Aortic valve stenosis is the most prevalent valvular heart disease in the Western population and is associated with ageing. Transcatheter aortic valve implantation (TAVI) has evolved as a routine treatment for patients with severe aortic valve stenosis at high or prohibitive risk for surgical aortic valve replacement $[1,2]$. TAVI-specific risk stratification models are currently lacking as surgical risk models poorly predict TAVI outcomes [3, 4].

Guidelines suggest using frailty characteristics in the selection of patients for TAVI $[1,2]$. Frailty is associated with diminished outcomes and increased risk of mortality and morbidity after surgical procedures. The Valve Academic Research Consortium uses the multifactorial definition of slowness, weakness, wasting and malnutrition, poor endurance, inactivity and limitation of independence [5]. There are numerous methods to assess frailty, although a standard and objective measurement method is lacking [6], and most consist of the quantification or dichotomisation of comorbidities. According to the Fried criteria, a patient is frail if three of the following criteria are met: a decline in lean body mass, strength, endurance, balance, walking performance and low physical activity 
[7]. Rockwood et al. defined frailty as an accumulation of deficits, and frailty is therefore quantified as the number of deficits a patient expresses as opposed to the nature of the health problems [8]. Frailty can also be described as the absence of resilience to react to (external) stressors such as a medical procedure or development of illness, but frailty and resilience are often used interchangeably [9].

The prognostic value of the different components of frailty in TAVI patients is as yet unclear.

The objective of this systematic review and metaanalysis was to find and pool frailty characteristics as predictors for 1-year mortality after TAVI.

\section{Methods}

\section{Search strategy}

We followed the PRISMA (Preferred Reporting Items for Systematic Reviews and Meta-Analyses) guidelines for reporting. The review was conducted in a twostep approach. First Ovid MEDLINE was searched to find randomised clinical trials on TAVI (last update: 12 April 2018) (Electronic Supplementary Material; search strategy, point 6). The full text of relevant randomised controlled trials (RCTs) was read to identify frailty parameters used in the studies. A more extensive list of the frailty variables found can be seen in the Electronic Supplementary Material (frailty characteristics search 1 RCT). We grouped variables together if they were similar or reflected the reciprocal definition such as body mass index (BMI), overweight and underweight.

Second, a search was performed in Ovid MEDLINE and Ovid Embase from inception to 12 April 2018 for TAVI and frailty (in general) or specific frailty parameters, previously identified in the RCTs (step 1). All searches were designed and performed by an experienced information specialist (J.L.), using both controlled terms (i.e. MeSH terms) and text words. There were no date, language or other restrictions, except for Embase, where we excluded MEDLINE records, editorials and conference abstracts. The records retrieved were imported and deduplicated in EndNote X7.5. The cited and citing references of the included studies were screened for additional relevant publications.

The complete search strategies can be found in the Electronic Supplementary Material (complete search).

\section{Eligibility criteria (and study selection)}

We included peer-reviewed, English-language original studies in humans. There were no restrictions as regards study participants, vascular access route, percutaneous valve type or other TAVI procedural characteristics. Primary outcome was all-cause 1-year mortality. Available data with described hazard ratios (HRs) for the primary outcome were included.

\section{Data extraction}

Two reviewers (M.S.v.M. and J.F.V.) independently screened title, abstracts and full texts of the identified publications using Rayyan [10]. Disagreements were solved by consensus or a third reviewer (M.M.V.). For each study included in the analysis, TAVI population demographics (age, gender, STS score and EuroSCORE), outcome descriptions (HR and 95\% confidence interval (CI) or other effect estimates) and length of follow-up were collected. Articles were finally included for pooled analysis if the described predictor was dichotomised with clear cut-off values based on common standards or clinical practice and reported adjusted HRs. If the same study was reported twice, only the earliest published results were used in the pooled analysis.

We analysed various reported frailty scores (dichotomised as frail/non-frail according to the scoring system used), any described chronic lung disease (CLD), kidney disease (estimated glomerular filtration rate $(\mathrm{eGFR})<30 \mathrm{ml} / \mathrm{min}$ or creatinine $>200 \mu \mathrm{mol} / \mathrm{l}$ ), underweight $\left(\mathrm{BMI}<20 \mathrm{~kg} / \mathrm{m}^{2}\right)$, hypoalbuminaemia $(<3.5 \mathrm{~g} / \mathrm{dl}$ or $<4 \mathrm{~g} / \mathrm{dl})$, independence (Katz activities of daily living (ADL) score of 1 or more deficits), gait speed ( $<6$ s on 5-m walking test) and anaemia (cut-off for males: <13 g/dl, females: <12 g/dl).

\section{Assessment of study quality and risk of bias}

Studies were first assessed for quality by two reviewers and marked as 'high' or 'low' quality, based on fulltext review of the methodology and reporting. A structured assessment of study quality was done using the Newcastle-Ottawa scale, in which sample selection, comparability and outcomes were scored (Electronic Supplementary Material, frailty characteristics search 1 RCT).

\section{Statistical analysis}

Articles were divided into subthemes based on the parameters found in the initial search for frailty and comorbidities with a described relation to frailty. Given the fact that there was wide variance between study designs and analysis, forest plots for random effects models were created to calculate summary effect estimates within the subthemes. Heterogeneity was assessed using the Cochran's Q test for heterogeneity. Statistical analysis was performed in R (version 3.3.3, http://www.r-project.org, R Foundation for Statistical Computing, Vienna, Austria) and the packages 'metafor' [11] and 'meta' [12]. Categorical variables are presented as numbers with percentages, means and standard deviations (SDs) or medians and interquartile ranges (IQRs) as appropriate. A $p$-value of $<0.05$ was considered statistically significant. 


\section{Results}

The first literature search identified 315 putative RCTs on TAVI articles. Multiple frailty parameters were found and categorised (Electronic Supplementary Material, frailty characteristics search 1 RCT). The second search (TAVI plus frailty parameters, identified by search 1) identified 1104 records, of which 49 articles were included in the meta-analysis and are presented in the PRISMA flow diagram (Fig. 1).

The main characteristics and findings of the studies included are summarised in Tab. 1. Some studies reported both on univariate and multivariate results of HR of the frailty characteristic for 1-year mortality. An overview and comparison of univariate and multivariate HR per variable can be found in the Electronic Supplementary Material (frailty characteristics search 1 RCT). There were no significant differences in pooled HRs between univariate and multivariate analysis.

Studies reported on specific frailty scores as well as comorbidities/conditions which are related to frailty. Articles which reported on frailty assessment as well as comorbidities were taken into the analysis for each subtheme.

\section{Chronic lung disease}

Twenty-seven studies [4, 13-39] (36,484 patients) were included in the analysis for the effect of CLD. One study was not used in the pooled analysis because the article did not report confidence intervals of the HR [35]. The pooled result of the random effects model was an HR 1.57 (95\% CI: 1.45-1.71), as shown in
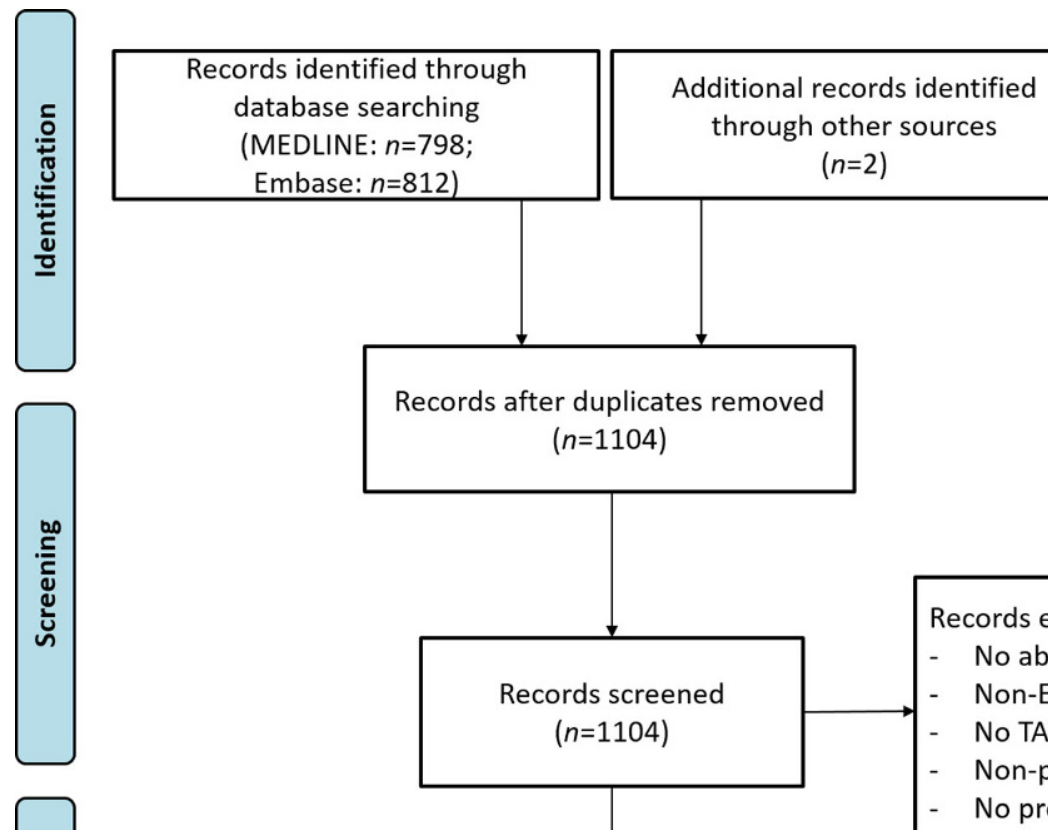

Records excluded ( $n=915)$

No abstract available $(n=116)$

Non-English language $(n=49)$

No TAVI population $(n=210)$

Non-peer-reviewed original article $(n=300)$

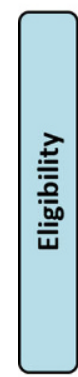

No predictors of one-year mortality analysed $(n=240)$

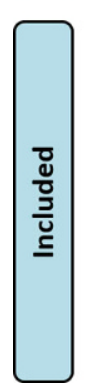

Studies included in

quantitative synthesis

(meta-analysis)

$(n=49)$

Fig. 1 Flowchart. TAVI transcatheter aortic valve implantation, $H R$ hazard ratio 
Table 1 Baseline characteristics of studies included in the analysis per frailty parameter, in order of the cumulative number of patients included

\begin{tabular}{|c|c|c|c|c|c|c|c|c|}
\hline Frailty parameter & $\begin{array}{l}\text { Chronic lung } \\
\text { disease }\end{array}$ & $\begin{array}{l}\text { eGFR } \\
30 \mathrm{ml} / \mathrm{min}\end{array}$ & $\begin{array}{l}\mathrm{BMl} \\
<20 \mathrm{~kg} / \mathrm{m}^{2}\end{array}$ & Hypoalbuminae & Frailty & Anaemia & Gait speed & $\begin{array}{l}\text { ADL indepen- } \\
\text { dence }\end{array}$ \\
\hline Number of studies & 27 & 8 & 7 & 5 & 9 & 5 & 3 & 2 \\
\hline $\begin{array}{l}\text { Cumulative number of } \\
\text { patients }\end{array}$ & 36,484 & 9993 & 9251 & 6347 & 5876 & 3746 & 1501 & 478 \\
\hline $\begin{array}{l}\text { Number of patients } \\
\text { (median, IQR) }\end{array}$ & $\begin{array}{c}476 \\
(350,1218)\end{array}$ & $\begin{array}{l}802 \\
(508,1181)\end{array}$ & $\begin{array}{l}1215 \\
(529,1756)\end{array}$ & $\begin{array}{l}1215 \\
(150,1215)\end{array}$ & $\begin{array}{l}498 \\
(339,734)\end{array}$ & $\begin{array}{l}549 \\
(182,1201)\end{array}$ & $\begin{array}{l}148 \\
(125,702)\end{array}$ & $\begin{array}{l}239 \\
(194,285)\end{array}$ \\
\hline Age (years), mean (SD) & $82.1(1.6)$ & $81.8(1.3)$ & $83.2(1.2)$ & $83.6(1.6)$ & $82.2(1.2)$ & $80.2(3.0)$ & $81.5(0.7)$ & $82.8(1.1)$ \\
\hline $\begin{array}{l}\text { Male gender (\%), mean } \\
\text { (SD) }\end{array}$ & $47.8(9.4)$ & $49.3(6.4)$ & $44.9(15.0)$ & 35.1 (12.1) & $48.0(6.6)$ & $51.4(2.4)$ & $\begin{array}{l}41.8 \\
(15.6)\end{array}$ & $40.6(4.0)$ \\
\hline $\begin{array}{l}\text { EuroSCORE I (\%), mean } \\
\text { (SD) }\end{array}$ & $20.3(3.21)$ & $\begin{array}{l}20.32 \\
(2.24)\end{array}$ & $\begin{array}{l}21.02 \\
(2.94)\end{array}$ & $\begin{array}{l}17.53 \\
(3.36)\end{array}$ & $\begin{array}{l}16.90 \\
(3.58)\end{array}$ & $\begin{array}{l}15.30 \\
(3.19)\end{array}$ & $\begin{array}{l}15.37 \\
(1.95)\end{array}$ & $16.85(3.32)$ \\
\hline $\begin{array}{l}\text { EuroSCORE II (\%), mean } \\
\text { (SD) }\end{array}$ & $7.63(1.56)$ & $\begin{array}{c}7.91 \\
(1.71)\end{array}$ & 7.30 (NA) & $\begin{array}{l}5.16 \\
(0.79)\end{array}$ & $\begin{array}{l}7.97 \\
(3.35)\end{array}$ & $(\mathrm{NA})^{4.00}$ & $(\mathrm{NA})^{5.10}$ & $\mathrm{NaN}(\mathrm{NA})$ \\
\hline STS (\%), mean (SD) & $8.78(2.88)$ & $\begin{array}{l}10.01 \\
(3.57)\end{array}$ & $\begin{array}{l}8.21 \\
(1.40)\end{array}$ & $\begin{array}{l}6.80 \\
(1.31)\end{array}$ & $\begin{array}{l}8.24 \\
(1.79)\end{array}$ & $\begin{array}{l}5.80 \\
(0.28)\end{array}$ & $\begin{array}{l}8.70 \\
(2.98)\end{array}$ & $6.10(0.14)$ \\
\hline
\end{tabular}

eGFR estimated glomerular filtration rate, $B M I$ body mass index, $A D L$ activities of daily living, IQR interquartile range, $S D$ standard deviation, STS Society of Thoracic Surgery score

Fig. 2a. Heterogeneity analysis showed that there was no significant difference in the between-study variance $(I: 27 \%, \tau=0.0106, p<0.10)$ (Fig. 2a).

\section{Chronic kidney disease (eGFR $<30 \mathrm{ml} / \mathrm{min}$ )}

Eight studies [4, 24, 29, 31, 32, 36, 40, 41] (9993 patients) were included in the analysis for patients with an eGFR below $30 \mathrm{ml} / \mathrm{min}$ as surrogate for chronic kidney disease (CKD). The pooled result was an HR of 1.96 (95\% CI: 1.68-2.30). Heterogeneity analysis showed that there was no significant difference in the between-study variance $\left(I^{2}=7 \%, \tau^{2}=0.0035, p=0.38\right)$ (Fig. 2b).

\section{Underweight $(B M I<20)$}

Seven studies [28, 34, 37, 39, 42-44] (9251 patients) were included in the analysis for patients who were underweight $\left(\mathrm{BMI}<20 \mathrm{~kg} / \mathrm{m}^{2}\right)$ at baseline. The pooled result of the random effects model was an HR of 1.49 (95\% CI: 1.10-2.03). There was a significant difference in the between-study variance $\left(I^{2}=86 \%, \tau^{2}=0.1263\right.$, $p<0.01$ ) (Fig. 2c).

\section{Hypoalbuminaemia}

Five studies [28, 45-48] (6347 patients) were included in the analysis regarding hypoalbuminaemia at baseline and resulted in a pooled $\mathrm{HR}$ of $1.77(95 \% \mathrm{CI}$ : 1.38-2.26). Heterogeneity analysis showed that there was no difference in between-study variance $\left(I^{2}=28 \%\right.$, $\tau^{2}=0.0214, p=0.24$ ) (Fig. 2d).

\section{Frail according to frailty score}

Nine studies [20, 32, 38, 40, 49-52] (5876 patients) were included in the analysis for patients who were frail according to a frailty score. Different frailty scores were used among the studies such as the Canadian Study of Health and Aging Scale [49]; the PARTNER frailty definition (a composite of different markers: serum albumin, dominant hand grip strength, gait speed, Katz ADL survey) [40, 50]; a cut-off on failing on three or more categories of the aforementioned PARTNER frailty markers, with the addition of BMI $<20 \mathrm{~kg} / \mathrm{m}^{2}$ [32]; at least three of five criteria: muscle weakness, slow gait speed, low physical activity, exhaustion and unintentional weight loss [51]; Rockwood scale [52]; Clinical Frailty scale or a physician perceived frailty status based on clinical status and comorbidities, no strict frailty definition but more a physician-perceived frailty status based on clinical status and comorbidities [20, 24, 38].

The pooled result was an HR of 2.16 (95\% CI: 1.56-3.00). Heterogeneity analysis showed that there was a significant difference in between-study variance $\left(I^{2}: 86 \%, \tau^{2}=0.1915, p<0.01\right.$ ) (Fig. $2 \mathrm{e}$ ).

\section{Anaemia}

Five studies [53-57] (3746 patients) were included in the analysis for anaemia using the predefined cutoff values. The pooled result was an HR of 2.09 (95\% CI: 0.93-4.66) and was not a significant predictor for 1-year mortality, but nevertheless showed a clear trend. Heterogeneity analysis showed that there was a significant difference in between-study variance ( $I^{2}$ : $95 \%, \tau^{2}=0.7797, p<0.01$ ) (Fig. 2f).

\section{Gait speed and ADL independence}

For both gait speed [49, 58, 59] and ADL independence $[49,60]$ only a limited number of articles could be included in the multivariate 1-year mortality analysis. For gait speed three studies were included in 
Fig. 2 a-h Forest plot per variable (multivariate HR for 1-year mortality after transcatheter aortic valve implantation). a Chronic lung disease. b Estimated glomerular filtration rate $<30 \mathrm{ml} / \mathrm{min}$. c Body mass index <20. d Hypoalbuminaemia. e Low frailty score. f Anaemia. g Low gait speed. $\mathbf{h}$ Deficiency in activities of daily life. $H R$ hazard ratio, TE treatment effect, seTE standard error treatment effect
Study

TE SeTE

[13] deBrito Jr, 2015

1.250 .2513

[14] Meneguz-Moreno, $2017 \quad 1.140 .5592$

[15] Mok, $2016 \quad 0.830 .1942$

[16] Henn, $2016 \quad 0.710 .3043$

[17] Hirji, $2017 \quad 0.620 .2677$

[18] Munoz-Garciae, $2013 \quad 0.620 .1713$

[19] Mok, $2013 \quad 0.610 .2714$

[20] Rodes-Cabau, $2012 \quad 0.610 .1582$

[21] Barbash, $2015 \quad 0.580 .3082$

[22] Lutz , $2017 \quad 0.57 \quad 0.2736$

[24] Thourani, $2016 \quad 0.540 .1288$

[25] Ribeiro, $2018 \quad 0.510 .2222$

[26] Konigstein, $2015 \quad 0.490 .2712$

[27] Urena, $2015 \quad 0.460 .1847$

[28] Shimura, $2017 \quad 0.440 .1838$

[29] Debonnaire, $2015 \quad 0.430 .2411$

[30] Bleiziffer, $2017 \quad 0.390 .1343$

[31] Moat, $2011 \quad 0.340 .1743$

[32] Steinvil , $2018 \quad 0.340 .3292$

[4] Ludman, $2015 \quad 0.300 .1011$

[34] Hioki , $2018 \quad 0.300 .2541$

[35] Grossi, $2008 \quad 0.26$

[36] Hemmann, $2013 \quad 0.250 .2745$

[37] Salizzoni, $2016 \quad 0.150 .1451$

[38] Codner, $2015 \quad 0.15 \quad 0.2752$

[39] Koifman, $2015 \quad 0.13 \quad 0.2147$

Random effects model

Heterogeneity: $I^{2}=27 \%, \tau^{2}=0.0106, p=0.10$

Study

[32] Steinvil , 2018

[40] Abramowitz, 2015

[36] Hemmann, 2013

[24] Thourani, 2016

[41] Saia, 2014

[29] Debonnaire, 2015

[4] Ludman, 2015

[31] Moat, 2011
TE seTE

1.250 .4207

0.950 .2625

0.940 .3774

0.810 .1430

0.600 .2064

0.570 .2677

0.450 .1516

0.440 .2784
[23] Gonzalez-Ferreiro, 20170.550 .1851

[33] Holmes Jr, $2015 \quad 0.330 .0549$

\section{Random effects model}

b

Heterogeneity: $I^{2}=7 \%, \tau^{2}=0.0035, p=0.38$

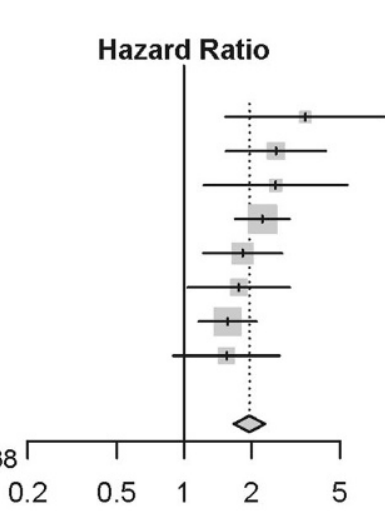

Study

[42]Pilgrim, 2012

[43] Koifman, 2016

[39]Koifman, 2015

[37]Salizzoni, 2016

[44]Yamamoto, 2013

[28]Shimura, 2017

[34]Hioki , 2018

\section{TE seTE}

0.970 .3798

0.900 .3385

0.640 .1641

0.370 .2562

0.300 .1356

0.210 .1871

$-0.060 .0272$
Hazard Ratio

$95 \% \mathrm{Cl}$ Weight

$3.50[2.14 ; 5.73] \quad 2.4 \%$

$3.14[1.05 ; 9.39] \quad 0.5 \%$

$2.29[1.57 ; 3.35] \quad 3.6 \%$

$2.03[1.12 ; 3.69] \quad 1.7 \%$

$1.86[1.10 ; 3.15] \quad 2.1 \%$

$1.85[1.32 ; 2.59] \quad 4.4 \%$

$1.84[1.08 ; 3.13] \quad 2.1 \%$

$1.84[1.35 ; 2.51] \quad 4.9 \%$

$1.79[0.98 ; 3.27] \quad 1.7 \%$

$1.77[1.04 ; 3.03] \quad 2.1 \%$

$1.74[1.21 ; 2.50] \quad 3.9 \%$

$1.72[1.34 ; 2.21] \quad 6.5 \%$

$1.67[1.08 ; 2.58] \quad 2.9 \%$

$1.63[0.96 ; 2.77] \quad 2.1 \%$

$1.59[1.11 ; 2.28] \quad 3.9 \%$

$1.55[1.08 ; 2.22] \quad 4.0 \%$

$1.54[0.96 ; 2.47] \quad 2.6 \%$

$1.48[1.14 ; 1.93] \quad 6.2 \%$

$1.41[1.00 ; 1.98] \quad 4.3 \%$

$1.41[0.74 ; 2.69] \quad 1.5 \%$

$1.39[1.25 ; 1.55] \quad 12.9 \%$

$1.35[1.11 ; 1.65] \quad 8.5 \%$

$1.35[0.82 ; 2.22] \quad 2.3 \%$

$1.30 \quad 0.0 \%$

$1.29[0.75 ; 2.21] \quad 2.1 \%$

$1.16[0.87 ; 1.54] \quad 5.6 \%$

$1.16[0.68 ; 1.99] \quad 2.0 \%$

$1.14[0.75 ; 1.74] \quad 3.1 \%$

$1.57[1.45 ; 1.71] 100.0 \%$

$95 \% \mathrm{Cl}$ Weight

$3.49[1.53 ; 7.96] \quad 3.6 \%$

$2.58[1.54 ; 4.32] \quad 9.0 \%$

$2.57[1.23 ; 5.38] \quad 4.5 \%$

$2.24[1.69 ; 2.96] \quad 27.3 \%$

$1.83[1.22 ; 2.74] \quad 14.2 \%$

$1.76[1.04 ; 2.97] \quad 8.7 \%$

$1.57[1.17 ; 2.11] \quad 24.6 \%$

$1.55[0.90 ; 2.67] \quad 8.1 \%$

$1.96[1.68 ; 2.30] 100.0 \%$

Random effects model

C

Heterogeneity: $I^{2}=86 \%, \tau^{2}=0.1263, p<0.01$

\section{Hazard Ratio}

95\% Cl Weight

$2.64[1.25 ; 5.56] \quad 9.1 \%$

$2.45[1.26 ; 4.76] \quad 10.2 \%$

$1.89[1.37 ; 2.61] \quad 16.1 \%$

$1.44[0.87 ; 2.38] \quad 12.8 \%$

$1.35[1.04 ; 1.76] \quad 17.0 \%$

$1.23[0.85 ; 1.77] \quad 15.3 \%$

$0.94[0.89 ; 0.99] \quad 19.4 \%$

$1.49[1.10 ; 2.03] 100.0 \%$ 
Fig. 3 Forest plot summarising all variables. eGFR estimated glomerular filtration rate, $B M I$ body mass index, $A D L$ activities of daily living

\begin{tabular}{|c|c|c|c|c|c|c|c|}
\hline Study & TE seTE & \multicolumn{2}{|c|}{ Hazard Ratio } & & & $95 \% \mathrm{Cl}$ & Weight \\
\hline [45] Kayama , 2018 & 1.550 .6146 & & 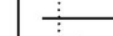 & & 4.73 & {$[1.42 ; 15.78]$} & $3.9 \%$ \\
\hline [46] Yamamoto, 2017 & 0.730 .2104 & & $\because$ & & 2.08 & {$[1.38 ; 3.15]$} & $23.9 \%$ \\
\hline [47] Bogdan, 2016 & $0.70 \quad 0.3378$ & & $\div$ & & 2.02 & {$[1.04 ; 3.92]$} & $11.6 \%$ \\
\hline [28] Shimura, 2017 & 0.520 .1972 & & $\div$ & & 1.68 & {$[1.14 ; 2.47]$} & $26.0 \%$ \\
\hline [48] Hermiller Jr, 2016 & 0.340 .1551 & & 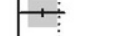 & & 1.40 & {$[1.03 ; 1.90]$} & $34.5 \%$ \\
\hline \multicolumn{2}{|l|}{ Random effects model } & & $\dot{\theta}$ & & \multirow[t]{3}{*}{1.77} & \multirow[t]{3}{*}[1.38;2.26]{} & \multirow[t]{3}{*}{$100.0 \%$} \\
\hline Heterogeneity: $I^{2}=28 \%, \tau^{2}$ & $2=0.0214, p=0.24$ & T & 1 & & & & \\
\hline 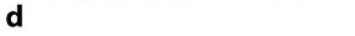 & 0.1 & 0.5 & 2 & 10 & & & \\
\hline Study & TE seTE & \multicolumn{2}{|c|}{ Hazard Ratio } & & & $95 \% \mathrm{Cl}$ & Weight \\
\hline [49] Dziewierz , 2017 & 3.670 .4607 & & & $\longrightarrow$ & 39.10 & {$[15.85 ; 96.46]$} & $6.9 \%$ \\
\hline [50] Green, 2015 & 0.880 .3797 & & $\because$ & & 2.40 & {$[1.14 ; 5.05]$} & $8.3 \%$ \\
\hline [32] Steinvil , 2018 & $0.80 \quad 0.2942$ & & $\div$ & & 2.22 & {$[1.25 ; 3.95]$} & $10.0 \%$ \\
\hline [40] Abramowitz, 2015 & 0.730 .2221 & & $\div$ & & 2.07 & {$[1.34 ; 3.20]$} & $11.6 \%$ \\
\hline [38] Codner, 2015 & 0.640 .2701 & & $\because$ & & 1.89 & {$[1.11 ; 3.21]$} & $10.5 \%$ \\
\hline [51] Rodriguez-Pascual, 2016 & 0.600 .1620 & & $\div$ & & 1.83 & {$[1.33 ; 2.51]$} & $12.8 \%$ \\
\hline [20] Rodes-Cabau, 2012 & 0.420 .1804 & & + & & 1.52 & {$[1.07 ; 2.16]$} & $12.4 \%$ \\
\hline [52] Seiffert, 2014 & 0.340 .0718 & & $+\vdots$ & & 1.41 & {$[1.22 ; 1.62]$} & $14.2 \%$ \\
\hline [24] Thourani, 2016 & 0.290 .1308 & & $\mp$ & & 1.33 & [ $1.03 ; 1.72]$ & $13.3 \%$ \\
\hline Random effects model & & & $\dot{\theta}$ & & 2.16 & {$[1.56 ; 3.00]$} & $100.0 \%$ \\
\hline Heterogeneity: $I^{2}=86 \%, \tau^{2}$ & $=0.1915$ & $0.1 \quad 0.5$ & 512 & 0 & & & \\
\hline
\end{tabular}

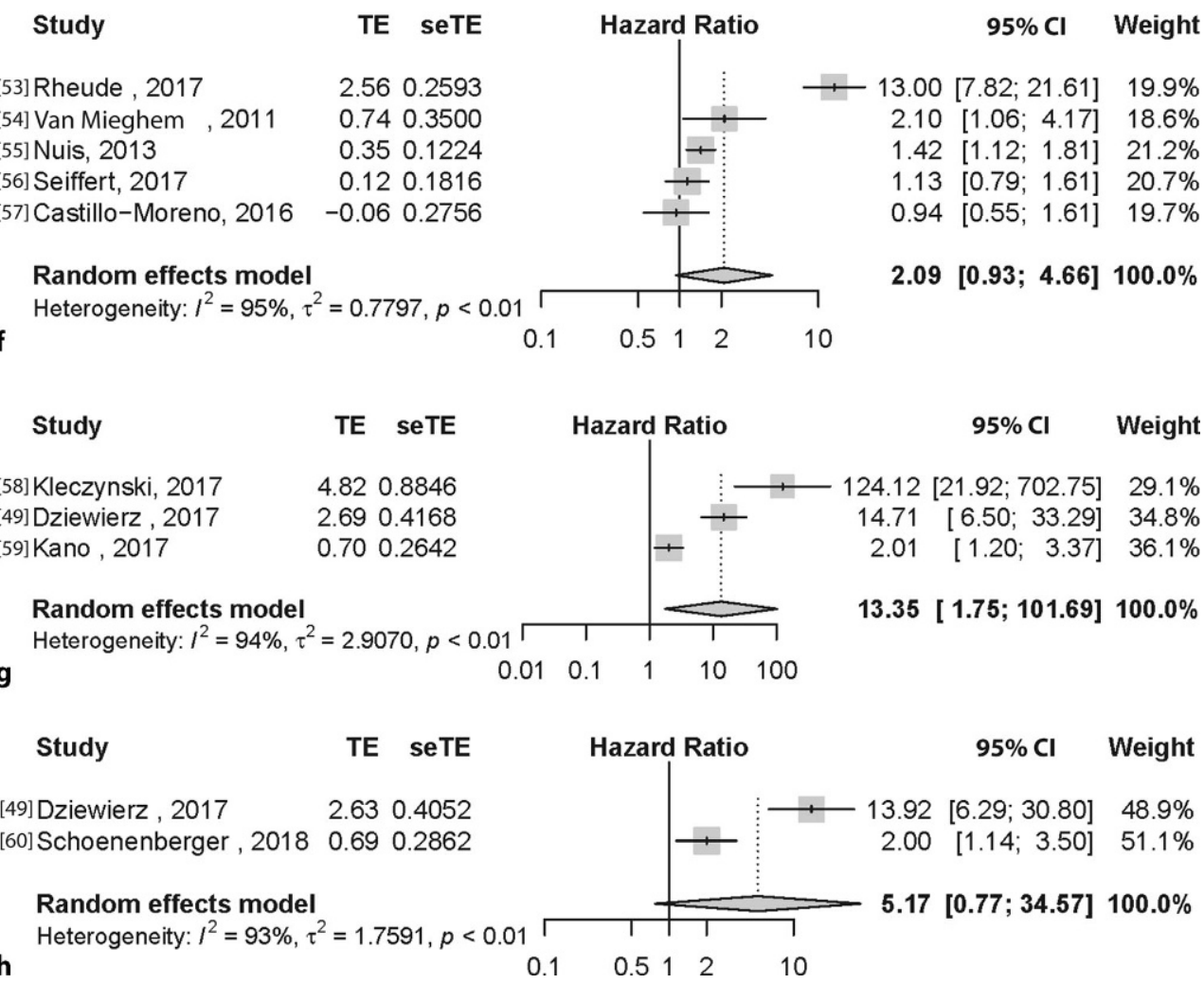

the meta-analysis (1501 patients) with a pooled HR of 13.35 (95\% CI: 1.75-101.69). Heterogeneity analysis showed that there was a significant difference in between-study variance $\left(I: 94 \%, \tau^{2}=2.9070, p<0.01\right)$ (Fig. 2g). For patients known to have any deficiency on the Katz ADL scale compared to those who did not, we included two studies, resulting in a pooled HR of 5.17 (95\% CI: 0.77-34.57) and heterogeneity analy- sis showed that there was a significant difference in between-study variance $\left(I: 93 \%, \tau^{2}=1.7591, p<0.01\right)$ (Fig. 2h).

Fig. 3 shows the summarised HRs of the different frailty subthemes, but these were not pooled together as the categories are not comparable. The strongest predictor of 1-year mortality was low gait speed, but this also had the largest confidence interval: HR 13.33, 
95\% CI: 1.75-101.49. Overall the HRs ranged from 1.49 to 13.33 .

\section{Discussion}

In this systematic review and meta-analysis we studied the relationship between multiple components considered as preoperative frailty parameters, aggregated frailty scores and all-cause 1-year mortality. Despite the fact that it is difficult to compare different subthemes of frailty we found that the most studied comorbidity is CLD, followed by CKD and underweight $\left(\mathrm{BMI}<20 \mathrm{~kg} / \mathrm{m}^{2}\right)$. Multiple comorbidities showed a strong association with worse 1-year mortality. Surgical risk scores are mostly used to differentiate between patients eligible for surgical aortic valve repair. In the first step of this systematic review, where we identified frailty characteristics used in RCTs, we focused on the manifestation of frailty, which is often described as diminished physical functioning (due to skeletal muscle loss of sarcopenia and osteopenia) and a decrease in cognitive functioning [61]. In our review we used frailty parameters which are measurable and can be easily used in daily clinical practice. The novelty of this study is that it is a comprehensive review and consisted of a two-step approach in which variables used as a surrogate for frailty in RCTs in TAVI patients were employed.

Other reviews have focused on the added value of assessing frailty in TAVI patients and the association with outcome after TAVI [62] or focused on pooling studies with a frailty assessment [63]. In our twostep approach we first identified subthemes within the frailty domain from RCTs in TAVI patients to include in our search comorbidities which are often seen as a parameter of the aggregated frailty term.

\section{Frailty scores}

Multiple frailty scores were used in the articles included in our pooled analysis. An earlier meta-analysis showed a clear association between dichotomised frailty scores and mortality after TAVI [63], but due to the differences in pooled studies and the structure of scales, meta-analysis and pooling of the results of non-dichotomised scales was not possible. Anand et al. also differentiated between subjective and objective assessment and found that both had a clear association with late ( $>30$ days after TAVI) mortality [63]. Since some of the frailty scores used were a physicianbased interpretation or an 'eyeballing' test, the implementation and objective scoring is challenging.

The frailty syndrome has an overlap with (co)morbidities and disability [64] and the parameters used often reflect a combination of those.

\section{CLD and CKD}

Most articles reported the presence of any type and severity of CLD and not necessarily based on pulmonary function testing or the effect of the lung disease on the actual physical functioning. CKD was defined by an eGFR $<30 \mathrm{ml} / \mathrm{min}$. Previous research has shown that although an eGFR $<60 \mathrm{ml} / \mathrm{min}$ is already considered to be CKD, the group below $<30 \mathrm{ml} / \mathrm{min}$ had a significant impact on 1-year mortality after TAVI [65].

\section{Malnutrition (underweight and/or hypoalbuminaemia)}

In our analysis we used underweight and hypoalbuminaemia as indicators for malnutrition. Overweight and obesity can also be considered as malnutrition categories [44]. There was, however, only limited data about obesity and, consistent with the literature on cardiothoracic surgery, the obesity paradox might also be valid for TAVI patients, as slight overweight is protective for mortality, whereas obesity is not. A metaanalysis on the effect of BMI on outcomes after TAVI found that 30-day mortality was not related to underweight, whereas long-term all-cause mortality was. Results in overweight patients $(\mathrm{BMI}>25)$ were similar to those in patients with normal weight. Obese patients (BMI >30) showed a significantly better longterm survival [66].

\section{Anaemia}

Anaemia was associated with worse outcomes after TAVI. A study not included in the meta-analysis, as the authors did not report on adjusted HR for 1-year mortality, but that is worth mentioning, is that by DeLarochellière et al., who reported that in their TAVI cohort two out of three patients had a preprocedural anaemia, of which $90.4 \%$ had a potentially correctable cause. However, only a limited number of patients received therapy [67]. In our results we also show that anaemia is associated with worse 1-year outcomes with a $77 \%$ increased risk.

\section{$A D L$ deficiencies and low gait speed}

For the two categories ADL deficiencies and gait speed we could include only a limited number of studies. Furthermore, there was a significant heterogeneity, making the results disputable. The Katz ADL score is a simple scoring tool which counts the number of deficits for six self-caring categories (e.g. dressing, feeding, mobility). Patients were completely independent if they needed assistance in none of the categories. Another approach would be to take disability (as the inverse of independence) [62]. One type of disability might influence outcomes more than another and more in-depth research in disability is warranted. 


\section{Other literature}

Anand et al. showed in their meta-analysis that objective frailty assessment identifies a group of more vulnerable patients than the 'end-of-the-bed' (or 'eyeballing') subjective assessment [63]. In our meta-analysis we did not include in the aggregated frailty category all of the articles we found by Anand et al., since the 1-year mortality was not always reported or the definition used was already covered by another of our frailty subthemes.

\section{Limitations}

Our study has several limitations. First, no studies randomised between frail and non-frail patients; patient selection in the reported studies might already be biased by underlying and unmeasured frailty, as TAVI patients are already considered a frail population. Second, we focused only on 1-year mortality; however frailty and comorbidities are likely also to influence longer-term mortality and morbidity. Thirdly, in our study we used dichotomous outcome variables from TAVI RCTs, instead of using the continuous scales. However, this facilitated the harmonisation of and increased the comparability of studies. We therefore included articles with the most common cut-off values, leading to the exclusion of articles with different cut-offs and those reporting continuous variables, as there is great variation between studies as regards study design and end-point definitions. Variables possibly serving as frailty characteristics but not used as frailty derivatives in TAVI RCTs, such as non-transfemoral access, were not studied in this review, which is a limitation.

In several categories (underweight, low frailty score, anaemia, low gait speed and ADL deficiency) a heterogeneity was observed and reflects the variance in results, thus supporting the need for larger prospective studies in the future.

\section{Future perspectives}

In order to better predict outcomes after TAVI and enhance patient selection, a dedicated TAVI risk score should be developed that incorporates the individual frailty parameters we pooled in this meta-analysis. Most of these parameters (kidney function, lung function, underweight, anaemia, hypoalbuminaemia) are already collected in standard routine TAVI care and therefore do not cause an extra burden to assess. The physical components gait speed and ADL independence might require more effort, but we show that they are predictive for outcome.

Recognising frail patients may facilitate identification of vulnerable patients and can lead to more patient-tailored disease management. The score used should be procedure-specific, as individual components of frailty might have a different weighting in total frailty dependent on the type of procedure a patient undergoes. Therefore, it is important to analyse the individual components or frailty parameters specifically for TAVI to come up with a TAVI-specific risk score. Thus frailty as a composite score should not be advocated to be part of a TAVI risk score, but the individual parameters of frailty contributing to outcomes should be taken because the relation between frailty and outcome is not a universal standard. These parameters can be differentiated between fixed and non-fixed risk factors based on the reversibility of the parameter. Prospective studies may be set up to investigate if an intervention to treat, for example, hypoalbuminaemia or physical training before the procedure improves outcomes.

\section{Conclusion}

In this meta-analysis we identified multiple frailty parameters used in TAVI research which were predictive for 1-year mortality. Chronic lung disease, chronic kidney disease, underweight, hypoalbuminaemia, a low frailty score, anaemia, low gait speed and an ADL deficiency were all associated with worse 1-year outcomes. Further research into the combination of these factors may help to more completely identify specific patients at risk when undergoing TAVI procedures.

Conflict of interest M.S. van Mourik, J.F. Velu, V.R. Lanting, J. Limpens, B.J. Bouma, J.J. Piek, J. Baan, J.P.S. Henriques and M.M. Vis declare that they have no competing interests.

Open Access This article is licensed under a Creative Commons Attribution 4.0 International License, which permits use, sharing, adaptation, distribution and reproduction in any medium or format, as long as you give appropriate credit to the original author(s) and the source, provide a link to the Creative Commons licence, and indicate if changes were made. The images or other third party material in this article are included in the article's Creative Commons licence, unless indicated otherwise in a credit line to the material. If material is not included in the article's Creative Commons licence and your intended use is not permitted by statutory regulation or exceeds the permitted use, you will need to obtain permission directly from the copyright holder. To view a copy of this licence, visit http://creativecommons.org/licenses/by/4.0/.

\section{References}

1. Otto CM, Kumbhani DJ, Alexander KP, Calhoon JH, Desai MY, Kaul S, et al. 2017 ACC expert consensus decision pathway for transcatheter aortic valve replacement in the management of adults with aortic stenosis: a report of the American college of cardiology task force on clinical expert consensus documents. J Am Coll Cardiol. 2017;69(10):1313-46.

2. Falk V, Baumgartner H, Bax JJ, De Bonis M, Hamm C, Holm PJ, et al. 2017 ESC/EACTS guidelines for the management of valvular heart disease. Eur Heart J. 2017;38(36):2739-91. https://doi.org/10.1093/eurheartj/ ehx391. 
3. Halkin A, Steinvil A, Witberg G, Barsheshet A, Barkagan M, Assali A, et al. Mortality prediction following transcatheter aortic valve replacement: a quantitative comparison of risk scores derived from populations treated with either surgical or percutaneous aortic valve replacement. The Israeli TAVR registry risk model accuracy assessment (IRRMA) study. Int J Cardiol. 2016;215:227-31.

4. Ludman PF, MoatN, de Belder MA, Blackman DJ, Duncan A, Banya W, et al. Transcatheter aortic valve implantation in the united kingdom: temporal trends, predictors of outcome, and 6-year follow-up: a report from the UK Transcatheter aortic valve implantation (TAVI) registry, 2007 to 2012. Circulation. 2015;131(13):1181-90.

5. Kappetein AP, Head SJ, Genereux P, Piazza N, van Mieghem NM, Blackstone EH, et al. Updated standardized endpoint definitions for transcatheter aortic valve implantation: the valve academic research consortium-2 consensus document. JAm Coll Cardiol. 2012;60(15):1438-54.

6. Schoenenberger AW, Stortecky S, Neumann S, Moser A, Juni P, Carrel T, et al. Predictors of functional decline in elderly patients undergoing transcatheter aortic valve implantation (TAVI). Eur Heart J. 2013;34(9):684-92.

7. Fried LP, Tangen CM, Walston J, Newman AB, Hirsch C, Gottdiener J, et al. Frailty in older adults: evidence for a phenotype. J Gerontol A Biol Sci Med Sci. 2001;56(3):M146-56.

8. Rockwood K, Song X, Macknight C, Bergman H, Hogan DB, McDowell I, et al. A global clinical measure of fitness and frailty in elderly people. Cmaj. 2005;173(5):489-95.

9. D'Avanzo B, Shaw R, Riva S, Apostolo J, Bobrowicz-Campos E, Kurpas D, et al. Stakeholders' views and experiences of care and interventions for addressing frailty and prefrailty: a meta-synthesis of qualitative evidence. PLOS ONE. 2017;12(7):E180127.

10. Ouzzani M, Hammady H, Fedorowicz Z, Elmagarmid A. Rayyan - a web and mobile app for systematic reviews. Syst Rev. 2016;5(1):210.

11. Viechtbauer W. Conducting meta-analyses in $\mathrm{R}$ with the metafor package. J Stat Soft. 2010;36(3):48.

12. Schwarzer G. Meta: an R packagefor meta-analysis. R News. 2007;7(3):40-5.

13. deBrito FS Jr., Carvalho LA, Sarmento-LeiteR, MangioneJA, Lemos P, Siciliano A, et al. Outcomes and predictors of mortality after transcatheter aortic valve implantation: results of the Brazilian registry. Catheter Cardiovasc Interv. 2015;85(5):E153-62.

14. Meneguz-Moreno RA, Ramos AI, Siqueira D, de CastroFilho A, Jatene T, Dias Jeronimo A, et al. Prognostic value of renal function in patients with aortic stenosis treated with transcatheter aortic valve replacement. Catheter Cardiovasc Interv. 2017;89(3):452-9.

15. Mok M, Allende R, Leipsic J, Altisent OA, Del Trigo M, Campelo-Parada F, et al. Prognostic value of fat mass and skeletal muscle mass determined by computed tomography in patients who underwent transcatheter aortic valve implantation. Am J Cardiol. 2016;117(5):828-33.

16. Henn MC, Zajarias A, Lindman BR, Greenberg JW, Melby SJ, Quader N, et al. Preoperative pulmonary function tests predict mortality after surgical or transcatheter aortic valve replacement. J Thorac Cardiovasc Surg. 2016;151(2):578-86.E1-2.

17. HirjiSA, Ramirez-DelValF, KolkailahAA, EjioforJI, McgurkS, Chowdhury R, et al. Outcomes of surgical and transcatheter aortic valve replacement in the octogenarians-surgery still the gold standard? Ann Cardiothorac Surg. 2017;6(5):453-62.

18. Munoz-Garcia AJ, del Valle R, Trillo-Nouche R, Elizaga J, Gimeno F, Hernandez-Antolin R, et al. The Ibero-American transcatheter aortic valve implantation registry with the corevalve prosthesis. Early and long-term results. Int J Cardiol. 2013;169(5):359-65.

19. Mok M, Nombela-Franco L, Dumont E, Urena M, DeLarochellière $\mathrm{R}$, Doyle $\mathrm{D}$, et al. Chronic obstructive pulmonary disease in patients undergoing transcatheter aortic valve implantation: insights on clinical outcomes, prognostic markers, and functional status changes. JACC Cardiovasc Interv. 2013;6(10):1072-84.

20. Rodes-Cabau J, Webb JG, Cheung A, Ye J, Dumont E, Osten M, et al. Long-term outcomes after transcatheter aortic valve implantation: insights on prognostic factors and valve durability from the Canadian multicenter experience. JAm Coll Cardiol. 2012;60(19):1864-75.

21. Barbash IM, Escarcega RO, MinhaS, Ben-Dor I, Torguson R, Goldstein SA, et al. Prevalence and impact of pulmonary hypertension on patients with aortic stenosis who underwent transcatheter aortic valve replacement. Am J Cardiol. 2015;115(10):1435-42.

22. Lutz M, von Ingersleben N, Lambers M, Rosenberg M, Freitag-Wolf S, Dempfle A, et al. Osteopontin predicts clinical outcome in patients after treatment of severe aortic stenosis with transcatheter aortic valve implantation (TAVI). Open Heart. 2017;4(2):E633.

23. Gonzalez-Ferreiro R, Munoz-Garcia AJ, Lopez-Otero D, Avanzas P, Pascual I, Alonso-Briales JH, et al. Prognostic value of body mass index in transcatheter aortic valve implantation: a "J"-shaped curve. Int J Cardiol. 2017;232:342-7.

24. Thourani VH, Forcillo J, Beohar N, Doshi D, Parvataneni R, Ayele GM, et al. Impact of preoperative chronic kidney disease in 2,531 high-risk and inoperable patients undergoing transcatheter aortic valve replacement in the PARTNER trial. Ann Thorac Surg. 2016;102(4):1172-80.

25. Ribeiro HB, Lerakis S, Gilard M, Cavalcante JL, Makkar R, Herrmann HC, et al. Transcatheter aortic valve replacement in patients with low-flow, low-gradient aortic stenosis: the TOPAS-TAVI registry. J Am Coll Cardiol. 2018;71(12):1297-308.

26. Konigstein M, HavakukO, ArbelY, Finkelstein A, Ben-Assa E, Leshem Rubinow E, et al. The obesity paradox in patients undergoing transcatheter aortic valve implantation. Clin Cardiol. 2015;38(2):76-81.

27. Urena M, Webb JG, Eltchaninoff H, Munoz-Garcia AJ, Bouleti C, Tamburino C, et al. Late cardiac death in patients undergoing transcatheter aortic valve replacement: incidence and predictors of advanced heart failure and sudden cardiac death. JAm Coll Cardiol. 2015;65(5):437-48.

28. Shimura T, Yamamoto M, Kano S, Kagase A, Kodama A, Koyama Y, et al. Impact of the clinical frailty scale on outcomes after transcatheter aortic valve replacement. Circulation. 2017;135(21):2013-24.

29. Debonnaire P, Fusini L, Wolterbeek R, Kamperidis V, van Rosendael P, van der Kley F, et al. Value of the "TAVI2-score" versus surgical risk scores for prediction of one year mortalityin 511 patients who underwent transcatheter aortic valve implantation. Am JCardiol. 2015;115(2):234-42.

30. Bleiziffer S, Bosmans J, Brecker S, Gerckens U, Wenaweser P, Tamburino C, et al. Insights on mid-term TAVR performance: 3-year clinical and echocardiographic results from the corevalveADVANCE study. Clin Res Cardiol. 2017;08:8.

31. Moat NE, Ludman P, de Belder MA, Bridgewater B, Cunningham $\mathrm{AD}$, Young $\mathrm{CP}$, et al. Long-term outcomes after transcatheter aortic valve implantation in high-risk patients with severe aortic stenosis: the U.K. TAVI (United Kingdom transcatheter aortic valve implantation) registry. JAm Coll Cardiol. 2011;58(20):2130-8. 
32. Steinvil A, Buchanan KD, Kiramijyan S, Bond E, Rogers T, KoifmanE, et al. Utility of an additive frailty tests indexscore for mortality risk assessment following transcatheter aortic valve replacement. Am Heart J. 2018;200:11-6.

33. Holmes DR Jr., Brennan JM, Rumsfeld JS, Dai D, O’Brien SM, Vemulapalli S, et al. Clinical outcomes at 1 year following transcatheter aortic valve replacement. JAMA. 2015;313(10):1019-28.

34. HiokiH, WatanabeY,KozumaK,Yamamoto M, NaganumaT, Araki M, et al. Risk stratification using lean body mass in patients undergoing transcatheter aortic valve replacement. Catheter Cardiovasc Interv. 2018;22:22.

35. Grossi EA, Schwartz CF, Yu PJ, Jorde UP, Crooke GA, Grau JB, et al. High-risk aortic valve replacement: are the outcomes as bad as predicted? Ann Thorac Surg. 2008;85(1):102-6. Discussion 7.

36. Hemmann K, Sirotina M, De Rosa S, Ehrlich JR, Fox H, Weber J, et al. The STS score is the strongest predictor of long-term survival following transcatheter aortic valve implantation, whereas access route (transapical versus transfemoral) has no predictive value beyond the periprocedural phase. Interact CardioVasc Thorac Surg. 2013;17(2):359-64.

37. SalizzoniS, D'Onofrio A, Agrifoglio M, ColomboA, Chieffo A, Cioni M, et al. Early and mid-term outcomes of 1904 patients undergoing transcatheter balloon-expandable valve implantation in Italy: results from the Italian transcatheter balloon-expandablevalveimplantation registry (ITER). Eur JCardiothorac Surg. 2016;50(6):1139-48.

38. Codner P, Orvin K, Assali A, Sharony R, Vaknin-Assa H, Shapira Y, et al. Long-term outcomes for patients with severe symptomatic aortic stenosis treated with transcatheter aortic valve implantation. Am J Cardiol. 2015;116(9):1391-8.

39. Koifman E, Magalhaes MA, Ben-Dor I, Kiramijyan S, Escarcega RO, Fang $C$, et al. Impact of pre-procedural serum albumin levels on outcome of patients undergoing transcatheter aortic valve replacement. Am J Cardiol. 2015;115(9):1260-4.

40. Abramowitz Y, Chakravarty T, Jilaihawi H, Kashif M, Zadikany R, Lee C, et al. Comparison of outcomes of transcatheter aortic valve implantation in patients $\geq 90$ years versus $<90$ years. Am J Cardiol. 2015;116(7):1110-5.

41. Saia F, LatibA, Ciuca C, Gasparetto V, Napodano M, SticchiA, et al. Causes and timing of death during long-term followup after transcatheter aortic valve replacement. Am HeartJ. 2014;168(5):798-806.

42. Pilgrim T, Kalesan B, Wenaweser P, Huber C, Stortecky S, Buellesfeld L, et al. Predictors of clinical outcomes in patients with severe aortic stenosis undergoing TAVI: a multistate analysis. Circ Cardiovasc Interv. 2012;5(6):856-61.

43. Koifman E, Kiramijyan S, Negi SI, Didier R, Escarcega RO, Minha S, et al. Body mass index association with survival in severe aortic stenosis patients undergoing transcatheter aortic valve replacement. Catheter Cardiovasc Interv. 2016;88(1):118-24

44. Yamamoto M, Mouillet G, Oguri A, Gilard M, Laskar M, Eltchaninoff $\mathrm{H}$, et al. Effect of body mass index on 30- and 365-day complication and survival rates of transcatheter aortic valve implantation (from the French aortic national corevalve and edwards 2 [FRANCE2] registry). Am J Cardiol. 2013;112(12):1932-7.

45. Kayama S, Aratake S, Sawamura S, Watanabe Y, Kozuma K. Medium and long-term prognosis of transcatheter aortic valve implantation from the perspective of left ventricular diastolicfunction. Cardiol J.2018;23:23.

46. Yamamoto M, Shimura T, Kano S, Kagase A, Kodama A, Sago M, et al. Prognostic value of hypoalbuminemia after transcatheter aortic valve implantation (from the Japanese multicenter OCEAN-TAVI registry). Am J Cardiol. 2017;119(5):770-7.

47. Bogdan A, Barbash IM, SegevA, Fefer P, Bogdan SN, Asher E, et al. Albumin correlates with all-cause mortality in elderly patients undergoing transcatheter aortic valve implantation. EuroIntervention. 2016;12(8):E1057-E64.

48. Hermiller JB Jr., Yakubov SJ, Reardon MJ, Deeb GM, Adams DH, Afilalo J, et al. Predicting early and late mortality after transcatheter aortic valve replacement. J Am Coll Cardiol. 2016;68(4):343-52.

49. Dziewierz A, Tokarek T, Kleczynski P, Sorysz D, Bagienski M, Rzeszutko L, etal. Impact of chronic obstructive pulmonary disease and frailty on long-term outcomes and quality of life after transcatheter aortic valve implantation. Aging Clin Exp Res. 2018;28(9):28.

50. Green P, Arnold SV, Cohen DJ, Kirtane AJ, Kodali SK, Brown DL, et al. Relation of frailty to outcomes after transcatheter aortic valve replacement (from the PARTNER trial). Am J Cardiol. 2015;116(2):264-9.

51. Rodriguez-Pascual C, Paredes-Galan E, Ferrero-Martinez AI, Baz-Alonso JA, Duran-Munoz D, GonzalezBabarro E, et al. The frailty syndrome and mortality among very old patients with symptomatic severe aortic stenosis under different treatments. Int J Cardiol. 2016;224:125-31.

52. Seiffert M, Sinning JM, Meyer A, Wilde S, Conradi L, VasaNicotera M, et al. Development of a risk score for outcome after transcatheter aortic valve implantation. Clin Res Cardiol. 2014;103(8):631-40.

53. Rheude T, Pellegrini C, Michel J, Trenkwalder T, Mayr NP, Kessler T, et al. Prognostic impact of anemia and irondeficiency anemia in a contemporary cohort of patients undergoing transcatheter aortic valve implantation. Int J Cardiol. 2017;244:93-9.

54. Van Mieghem NM, Nuis RJ, Tzikas A, Piazza N, Schultz C, Serruys PW, et al. Prevalence and prognostic implications of baseline anaemia in patients undergoing transcatheter aortic valve implantation. EuroIntervention. 2011;7(2):184-91.

55. Nuis RJ, Sinning JM, Rodes-Cabau J, Gotzmann M, van Garsse L, Kefer J, et al. Prevalence, factors associated with, and prognostic effects of preoperative anemia on short- and long-term mortality in patients undergoing transcatheter aortic valve implantation. Circ Cardiovasc Interv. 2013;6(6):625-34.

56. Seiffert M, Conradi L, Gutwein A, Schon G, Deuschl F, Schofer N, et al. Baseline anemia and its impact on midterm outcome after transcatheter aortic valve implantation. Catheter Cardiovasc Interv. 2017;89(1):E44-E52.

57. Castillo-Moreno JA, Garcia-Escribano IA, Martinez-Pascual-De-Riquelme M, Jaulent-Huertas L, Dau-Villarreal DF, Rubio-Paton R, et al. Prognostic usefulness of the 6-minute walk test in patients with severe aortic stenosis. Am J Cardiol. 2016;118(8):1239-43.

58. Kleczynski P, Dziewierz A, Bagienski M, Rzeszutko L, Sorysz D, Trebacz J, et al. Impact of frailty on mortality after transcatheter aortic valve implantation. Am Heart J. 2017;185:52-8.

59. Kano S, Yamamoto M, Shimura T, Kagase A, Tsuzuki M, Kodama A, et al. Gait speed can predict advanced clinical outcomes in patients who undergo transcatheter aortic valve replacement: insights from a Japanese multicenter registry. Circ Cardiovasc Interv. 2017;10(9):e5088. https:// doi.org/10.1161/CIRCINTERVENTIONS.117.005088.

60. Schoenenberger AW, Moser A, Bertschi D, Wenaweser P, Windecker S, Carrel T, et al. Improvement of risk prediction after transcatheter aortic valve replacement by combining 


\section{Review Article}

frailty with conventional risk scores. JACC Cardiovasc Interv. 2018;11(4):395-403.

61. Mack M. Frailty and aortic valve disease. J Thorac Cardiovasc Surg. 2013;145(3):S7-10.

62. Puri R, Iung B, Cohen DJ, Rodes-Cabau J. TAVI or no TAVI: identifying patients unlikely to benefit from transcatheter aortic valve implantation. Eur HeartJ. 2016;37(28):2217-25.

63. Anand A, Harley C, Visvanathan A, Shah ASV, Cowell J, Maclullich A, et al. The relationship between preoperative frailty and outcomes following transcatheter aortic valve implantation: a systematic review and meta-analysis. Eur Heart J. 2017;3(2):123-32.

64. Fried LP, Ferrucci L, Darer J, Williamson JD, Anderson G. Untangling the concepts of disability, frailty, and comorbidity: implications for improved targeting and care. J Gerontol A Biol Sci Med Sci. 2004;59(3):255-63.
65. van Mourik MS, Vendrik J, Abdelghani M, van Kesteren F, Henriques JPS, Driessen AHG, et al. Guideline-defined futility or patient-reported outcomes to assess treatment success after TAVI: what to use? Results from a prospective cohort study with long-term follow-up. Open Heart. 2018;5(2):E879

66. Sannino A, Schiattarella GG, Toscano E, Gargiulo G, Giugliano G, Galderisi M, et al. Meta-analysis of effect of body mass index on outcomes after transcatheter aortic valve implantation. Am J Cardiol. 2017;119(2):308-16.

67. DeLarochellièreH, Urena M, Amat-Santos IJ, Ribeiro HB, Allende R, Laflamme L, et al. Effect on outcomes and exercise performance of anemia in patients with aortic stenosis who underwent transcatheter aortic valve replacement. Am J Cardiol. 2015;115(4):472-9. 


\title{
Advertisement placed here.
}

\author{
ces bohn \\ CL van loghum
}

Houten 2020 


\title{
Advertisement placed here.
}

\author{
ces bohn \\ CL van loghum
}

Houten 2020 